\title{
Human Communication as a Correlate of the Essence of Man: A Philosophical Perspective
}

\section{Onjefu $\mathrm{O}^{1^{*}}$ and Olalekan $\mathrm{AG}^{2}$}

${ }^{1}$ Department of Mass Communication, Kwara State University, Malete, Nigeria

${ }^{2}$ Department of Mass Communication, Al-Hikmah University, Ilorin, Nigeria

*Corresponding author: Onjefu O, Department of Mass Communication, Kwara State University, Malete, Nigeria, Tel: 08036636139; E-mail: Okidu2002@yahoo.com

Received date: January 25, 2016; Accepted date: February 15, 2016; Published date: February 19, 2016

Copyright: ( 2016 Onjefu O, et al. This is an open-access article distributed under the terms of the Creative Commons Attribution License, which permits unrestricted use, distribution, and reproduction in any medium, provided the original author and source are credited.

\begin{abstract}
This paper, as an attempt at espousing the view that human communication reveals the essence of man, constitutes a contribution to the on-going philosophical discussions on understanding the meaning and the nature of man. The paper examines the idea of human communication from a philosophical perspective. It particularly explores the concepts of language, symbols and meaning as determinants of human existence through communication, and concludes that the whole essence of human interactions and attempts at persuasion of individuals by individuals, groups, institutions etc lie in the manipulation of meanings through symbols, codes and signs as constituents of language.
\end{abstract}

Keywords: Human; Communication; Symbols; Language

\section{Introduction}

Since the end of the nineteenth century, philosophical discussions of knowledge have shifted from general descriptions of the phenomenon to questions of understanding and meaning [1]. The discussions of the uses of communication lead to considerations of understanding, meaning and. nature of man. The results of this change are evident in the analysis of the media, the form and content of interpersonal communication, the nature of group and organizational communication etc. This paper is an attempt to contribute to the discussions. The aim of the paper is to project the philosophical perspective that communication reveals, in part, what man intrinsically is. Specifically, the paper will attempt to answer the question: does human communication reveal the essence of man?

Apart from the introduction and conclusion, as well as the theoretical framework, the paper is organized around three major sections. The first section deals with the definition of major concepts used in the paper. The second section takes a look at man, language symbols and meaning. And the third section dwells on philosophical views on the relationship between communication and the essence of man.

\section{Theoretical Framework}

Discussing the issue of meaning and its influence in human communication, the subject matter of this paper finds relevance in the Symbolic Interaction Theory. This theory is therefore used to frame the thrust of discussion in this paper. The Symbolic Interaction Theory has three basic themes and seven related assumptions. The three themes are: the importance of self-concept; and the relationship between the individual and the society. The seven assumptions of the theory are that:

- Humans act towards others on the basis of meanings those individuals have for them. Because individual are perceived as choice makers, human behavior is viewed as loop of conscious thought and behavior between stimuli and response people exhibit to those stimuli.

- Meaning is created in interaction between people. Meaning can only exist when people share common interpretations of the symbols they exchange in interaction.

- Meanings are modified through an interpretive process. The first step is intrapersonal communication in which an individual points out to her or himself the things that have meanings in the context in which they find themselves.

- Individuals develop self-concept through interaction with others. Self-concept is defined as the relative stable set of perceptions that people hold of themselves.

- Self-concept provides an important motive for behaviour.

- People and groups are influenced by culture and social processes. Social norms constrain individual behaviour and self-concept.

- Social structure is worked out through social interaction. Symbolic interaction acknowledges that individuals can change social situations.

The foregoing theoretical assumptions or postulations are pertinent in the discussions that follow on the philosophical bases of communication as a determinant of the essence of man.

\section{Conceptual Clarifications}

\section{The meaning of philosophy}

The word 'philosophy' derives from two Greek words, 'philo' and 'sophia' which means 'love' and "wisdom' respectively. Hence, the etymological definition of philosophy is love of wisdom' [2]. Apart from the etymological definition, which gives the literal meaning, philosophy has been defined in so many ways. Aristotle defines philosophy as knowledge of essence in itself or of the essence of all that exists. The metaphysical systems of the middle ages in Europe and modern times also define philosophy as the study of being. In modern 
western philosophy this definition is accepted by Neo-Thomaist, a substantial number of Christian spiritualists, and also the existentialists, and Nicolai Harmann's 1882 new Ontology [3].

Buddha in ancient India defines philosophy as the study not of being but of cognition, or morality or happiness, or of man in general.. In ancient times, this definition constantly competed with opposing definitions of philosophy both in metaphysics and ontology. David Hume, a British Philosopher, questioned the existence of any objective reality that was independent of the consciousness. He thus limited the sphere of philosophical inquiry to the study of mental activity, particularly the act of knowing. Hume was not interested in knowledge in general, but in the study of man, in self-knowledge. In this he saw the way of overcoming the age-long errors in philosophy and arranging human life on rational lines [3]. Kant, a German Philosopher who, unlike Hume, acknowledges the existence of a reality independent of the knower, nevertheless dismisses the problem of being on the grounds that it is unknowable. Accordingly, he defined philosophy as a doctrine of the absolute boundaries of all possible knowledge. These boundaries, according to Kant, are determined by the very mechanism of cognition: it is a priori form which may be applied only to sensory data but not to the transcendental 'thing-initself. The thing in itself to Kant is beyond human knowledge [3].

The definition of philosophy as the study of cognition is also developed by the positivists, who argue that philosophy should be reduced to the theory of knowledge, on grounds that all other possible objects of cognition are studied by specialized science and there is nothing left for philosophy but to study science itself, the fact of knowledge. From Hegel's point of view, a philosophical system is an encyclopedia of philosophical sciences, interpreting even questions studied by the specialized sciences but its own peculiar speculative position which is beyond their scope. Hence, according to Hegel, philosophy can be primarily defined as 'thinking examination of objects'. In his view, philosophy constitutes a peculiar mode of thought. A mode of thought by which it becomes cognition, and cognition by means of concepts. Hegel's definition is consistent with the purpose of this paper. Philosophy involves reflection, analysis, criticism and evaluation.

\section{The Idea of Human Communication}

The idea of human communication is derived from the notion of 'sharing meaning within, between and among people. However, there have been numerous attempts to define human communication. For instance, Cronkite observes that "human communication has occurred when a human being responds to a symbol." Dance on his part looks at human communication as "the transmission of information, ideas, emotions, skills etc. by the use of symbols, words pictures, figures, graphs, etc." Miller, in conceiving human communication, points out that, "communication has its central interest in those behavioral situations in which a source(s) transmits a message to receivers) with consciousness intent to affect the latter's behaviors." The definitions provided by Cronkite, Dance and Miller above are different from the one advanced by Infant, Rancer and Womack. According to them, "communication occurs when humans manipulated symbols to stimulate meaning in others". Their definitions differ from those above in that it emphasizes both sender and receiver. It also calls attention to the symbolic and intentional nature of communication. However, the definition of human communication as "shared meaning" advanced by Baran, Mclrtyre and Meyer is most compatible with the focus of this paper [4]. Human beings share some of the meanings of words or gestures because they speak the same language. This idea of shared meanings in human communication is the thrust of one of the postulations of the symbolic interaction theory. The postulation is to the effect that "meaning is created in interaction between people. Meaning can only exist when people share common interpretations in the symbols they exchange in interaction".

It has also been observed that human communication occurs in a context, involves co-orientation, individual interpretation, and a process (Ibid). Communication has components (source, message, channel and receiver) which interact with one another, and the specific nature of that interaction produces specific consequences. How much meaning is shared, what meanings are shared and when sharing takes place are all variables which can function in different combinations. The idea that human communication is contextual as well as operates through an interpretive process, is a well-accepted idea in communication theory. The explanations of the symbolic interaction theory are particularly instructive in this respect. Specifically, the theory partly postulates that "meanings are modified through an interpretive process. The first step is interpersonal communication in which an individual points out to her or himself the things that have meanings in the context in which they find themselves. There also is, rather, an extensive agreement on the contexts. Generally, the contexts considered include, intrapersonal, interpersonal, group, organizational, public, mass, intercultural, family, health and political Communication.

\section{The Notion of Essence of Man}

Before we ask "what is the essence of man?", we might as well ask: what is man? According to Allen, man is a complex 'machine', an interaction of chemical and physical properties we do not fully understand." In an attempt to define man, Saint Paul pointed out that man is composed of body, soul and spirit. According to Olst, the essence of man is not his body. The body, according to him, is an aid to something else - an aid to his feelings and thoughts. He further explains that his thoughts in their turn can be viewed as an aid to his will, or conversely, there is a part of his consciousness that uses his thought. He continues by saying that this consciousness, this part of himself, is thus more essential than his thought. He concludes by saying that the essence of man goes beyond the mind and the body.

According to Plato, reality has two sides. The material (i.e. physical) side and the immaterial (spiritual) side. In Plato's philosophy, everything including man is made up of matter and form or essence. Matter changes, it comes and goes i.e. it is destructible, it is finite and perceived by the senses. On the other hand, the forms are eternal, indestructible, infinite, changes and can only be known by reason. In his view, the existence of things depends on their form or idea. The immaterial aspects of things constitute their real nature, and are therefore superior. They provide what Plato calls the essence or form of the things. Plato even postulates a world of essence or form from which all sensible objects derive.

Aristotle, Plato's student for 20 years, disagrees with Plato on the ground that our knowledge of that which is immaterial depends on the particular things we see. He holds matter to be superior and primary Being, because the immaterial (i.e. forms, essence) are abstracted from particular things. He believes that we know immaterial things because we first of all experience them in particular objects of the world. The Hindu Group believes that character is the essence of man. According to the group, character is the total of a person's values, beliefs and 
personality. It is reflected in our behaviour, in our actions. Wezen offers the most simplistic and suitable definition. He views essence of man as what man intrinsically is - his totality, his uniform being. He goes further to say that what relates to man's specific identity "is the dynamical law that has directly generated man."

\section{Man, Language, Symbols and Meaning}

Man communicates in ways that are very different from those used by any other species on the planet. Specifically, man communicates with some form of learned "and shared verbal and nonverbal language that is part of a culture that has accumulated and grown increasingly complex over time. The substance of language is symbol. A symbol is a word, action, or object that 'stands for' and arouses a standardized internal meaning in people in a given language community. By an established convention (a well-established rule), each symbol - such as "woman", "man", or even the complex term interrogation, is supposed to arouse parallel, that is, similar, internal-meaning - experiences in everyone who uses it. In addition, actions such as gestures and facial expressions - can be governed by meaning as dictated by conventions. The same is true of certain objects, such as cross, a star or a wedding ring.

According to Rivers, Petterson and Jesen, "Man is the creature we know to react not only to his real physical environment but also symbolic environment of his own making". They further point out that, "man, by creating a symbolic world, has given reality a dimension known only to him." In their opinion, what all this means is that "man does not confront reality first hand. Instead of always dealing with things themselves, as other animals do, man develops ideas about things." They continue by pointing out that, "man so envelop himself in linguistic forms,

in artistic images, in mythical symbols, or in religious rites that he cannot see or

know anything except through his symbolic system." According to them, the

framework and structure of reality are not something that man can touch or directly see because they are intellectual, and man can perceive them only indirectly through symbols.

As Rivers, Pettersen and Jesen points out, this distinctive mark of man's life is not necessarily related to his rationality (or his irrationality). But man sometimes use symbols in unusual ways, and clear communication is almost impossible. This raises the question of meaning, which is an important subject matter in this section. The foregoing contentions of Rivers Petterson and Jesen find relevance in the postulation of the symbolic interaction theory to the effect that 'humans act towards others on the basis of meanings those individuals have for them. Because individual are perceived as choice makers, human behavior is viewed as loop of conscious thought and behavior between stimuli and response people exhibit to those stimuli.

The concept of meaning operates on at least two basic levels: denotation and connotation. Denotation refers to agreed-upon meaning or dictionary meaning for a term. Connotation refers to an individualized or personalized meaning that may be emotionally laden. Denotative meanings are understood and shared by a large number of people. They are meanings people hold because of a common social experience with a symbol. For example, the word computer is generally understood similarly by others through their essentially common experience with these objects, connotative meanings may be held by a single person or very small number of people. They are meanings others have come to hold because of a personal or individual experience. People sometimes deliberately use the connotative meaning of a word for a particular purpose. For instance, when discussing economy, politicians may use the word hunger to gain a desired response.

In his seminar paper, "meaning", first published in 1957, Herbert Paul Grice drew a distinction between what he called natural meaning and what he called, non-natural meaning. According to him, natural meaning is the kind of meaning that we are speaking of when we say something like, "those spots mean measles" or "A shiny coat in a dog means health". Non-natural meaning is the kind of meaning we speak of when we say "those three rings on the bell (of the bus) mean that the bus is full" or by saying that the child looked guilty, he meant that the child was in fact guilty". This analysis takes us to the major question the paper attempts to answer - does communication reveal the essence of man?

\section{Communication and the Essence of Man}

Jean-Paul Sartre offered a dynamic view of how communication correlates with the essence of man when he said, "I am what I say". He continued by saying that "language is not an instinct of the constituted human creature, nor is it an invention of our subjectivity ... it forms part of the human condition." He further pointed out that, "the man who talks is beyond words" [5]. Agreeing with Satre, Richard Weaver, in a public lecture delivered at the University of Oklahoma in 1962 titled, "Language is Sermonic", said that every use of speech, oral and written, exhibits an attitude, and an attitude implies an act pointing out that the saying, "thy speech betrayeth thee" is aphoristically true. He continued by saying that your speech reveals your disposition, first by what you choose to say, then by the amount you decide to say, and so on down through the resources of linguistic elaboration and intonation.

In his contribution to the discussions on logical positivism, Ayer [6] elaborated on these notions. According to him, " transference of information, in a very broad sense of this term, which may be taken to include, not merely the imparting of news, in a factual sense but also the expression of feelings, wishes, commands, desires, or whatever it may be ..."

Carrying the view further, Adidi Uyo in his "The Weight of Words", published in the Guardian newspaper observed that, "It is better to be silent and be considered a fool than to open one's mouth and remove all doubts." He went further to say "one way to tell the sage from a moron is to examine the words that flow from their mouths... It could be very telling." He went further to explain:

"It is true what Shakespeare said: "There is no art to find the mind's construction on the face". But anybody who is vast in psycholinguistics could assail to find the mind's construction via a person's diction. The words that flow from a person's mouth ... are a window to his mind, for those words, at worst, mirror or reflect what is in his or her mind: at best represent them. In short, given a person's words, we could try to deconstruct him or her mentally, that is, attempt to analyze or decipher his or her state of mind.

Using the quest for a national sovereign conference in Nigeria as an example, Uyo observed that President Obasanjo's use of the word 'Dialogue' which is not the same thing as CONFERENCE tells clearly the president's disposition. We find similar evaluation embodied in all 
the sacred literatures of the world, not least in the Christian scriptures, as witnessed by Jesus' challenging words to the Pharisees:

Either makes the tree good, and his fruit good, or else make the tree corrupt, and his fruit corrupt: for the tree is known by his fruit. $\mathrm{O}$ generation of vipers, how can ye, being evil, speak good things. For out of the abundance of the heart the mouth speaketh. A good man out of the good treasure of the heart bringeth forth good things, and an evil man out of the evil treasure bringeth forth evil things.

Except in situations whereby man deliberately decides to be deceptive, what man intrinsically is manifesting itself through communication? What we are greatly influences our communication. For instance, if you are a success, you say this in many ways and on many occasions. Your verbal message reflects optimism and unpretentious confidence. Non-verbally, your posture, gestures, tone of voice, and facial expression say you are a success. However, people sometimes exude too much confidence. This communication is also revealing. Other people say quite clearly in their verbal message that they are pessimistic about their future or that they are helpless in their environments. As a way of asking for help, such people sometimes use facial expressions to say they are depressed, a message which is also communicated by posture and gesture [7-11].

As the Bible says: out of the abundance of the heart, the mouth speaketh, not what a man fancies himself to be, but what he is deep within. Education, religious or social backgrounds, are shaping factors, but not deciding issues, for man as Vanlear has pointed out, is more than his environment.

\section{Conclusion}

This paper has attempted to restate the philosophical perspective that Human Communication reveals the essence of man. The purpose of the paper is to further expose the view in an attempt to contribute to the on-going philosophical discussions on understanding, meaning and the nature of man. The meaning of words is always the utterer. As Grice [12] has pointed out, speakers (utterer's) meaning, so defined, has to be strictly distinguished from what might be called the conventional meaning of a speaker's words. The place of conventional meaning of language appears to be that it constitutes a feature of words that speakers might exploit. Largely as a result of that, there is need for us to turn our attention away from explicating the meaning of symbols to explicating the essence of the maker of the symbols because the meaningfulness of symbols derives from the maker. Words correlate strongly with their origins.

\section{References}

1. Caponigri R (1971) Philosophy from the age of positivism to the age of analysis. University of Notre Dame Press, Indiana.

2. Passmore J (1957) A Hundred Years of Philosophy. Penguin, England.

3. Ogundowole EK (2002) Philosophy and Logic: A Student Companion. Department of Philosophy, University of Lagos, Lagos.

4. Baran B, Malrtyre W, Meyer R (1984) Self, Symbols and Society. Odison Wesley Publication, USA.

5. Grant M (1980) The Classical Greeks. Macmillan, New York.

6. Alfred JA (1968) The origin of pragmatism, baltimore. Inter Press.

7. Fisher A (1978) Perspectives on human communication. Macmillan, New York.

8. David KB (1960) The Process of Communication. Holt, Rinehart, and Winston, New York.

9. Lock J (1979) An Essay Concerning Human Understanding. Oxford University Press, Britania.

10. Weaver R (1963) Language is sermonic. In: Nebsgall R, Dimensions of Rhetorical Scholarship. University of Oklahoma, Norman.

11. Wilbur S (1971) The nature of communication between humans. In: Schramm W, and Roberts D (eds) The Process and Effects of Mass Communication. University of Illinois Press, Urbana.

12. Grice HP (1982) Meaning revisited in Smith Mutual Knowledge. Academic Press, USA. 